\title{
Assessment of Knowledge and Attitude in a Sample of Patients with Rheumatoid Arthritis and Its Association with Disease Activity and Severity: A Cross-Sectional Study
}

\author{
Sami Salman', Ahmad SAlnuaimi'2, Nizar Abdul Lateef', Rana Kadhum1 \\ ${ }^{1}$ Rheumatology Unit, Department of Medicine, College of Medicine, University of Baghdad, Baghdad, Iraq \\ ${ }^{2}$ Community Medicine Department, College of Medicine, University of Baghdad, Baghdad, Iraq \\ Email: ssshihab2@gmail.com
}

Received 24 August 2014; revised 24 September 2014; accepted 24 October 2014

Copyright (C) 2014 by authors and Scientific Research Publishing Inc.

This work is licensed under the Creative Commons Attribution International License (CC BY).

http://creativecommons.org/licenses/by/4.0/

(c) () Open Access

\section{Abstract}

Background: Rheumatoid arthritis (RA) is a chronic and disabling disease that has a major impact on the lives of patients. Objectives: To test the patients' knowledge about their disease, its treatment, its complications, and if this affects severity of the disease as measured by the disease activity index (DAS 28). Patients and Methods: A sample of 100 patients with RA who met the Criteria of American College of Rheumatology for RA agreed to participate in this study over the period September 2011-March 2012. Patients' data were obtained by personal interview. The questionnaire included demographic characteristics and the patients' knowledge about their disease. The disease activity was measured using standard (DAS28). Results: Thirty three percent of the patients didn't have an idea about their disease, $20 \%$ didn't know the reason for the investigations, $49 \%$ didn't know the treatment and $40 \%$ didn't know the side effects of their medications. Most patients had a high disease activity index, and there was a poor correlation between patients' educational level and the disease activity. Conclusions: Neither the educational level nor the frequency of hospital admissions had effects on the knowledge about this disease. As most patients had a high disease activity, a better knowledge may improve disease control and prevent complications.

\section{Keywords}

Rheumatoid Arthritis, Disease Burden, Disease Awareness, Patient's Education, Patient's Knowledge, Socio-Economic Factors, Disease Activity Index

How to cite this paper: Salman, S., SAlnuaimi, A., Lateef, N.A. and Kadhum, R. (2014) Assessment of Knowledge and Attitude in a Sample of Patients with Rheumatoid Arthritis and Its Association with Disease Activity and Severity: A Cross-Sectional Study. Open Journal of Rheumatology and Autoimmune Diseases, 4, 226-234. 


\section{Introduction}

Rheumatoid arthritis (RA) is a chronic autoimmune disease that causes inflammation and deformity of the joints. Systemic problems may also develop, vasculitis, development of nodules (rheumatoid nodules) in various parts of the body, lung disease, blood disorders, and osteoporosis. The disease affects all ethnic groups throughout the world; it is a heterogeneous and progressive autoimmune disease [1].

Prevalence figures vary depending on the source of information and the method of classifying rheumatoid arthritis. Definite RA was observed in 1\% of population samples in Iraq [2]. The greatest decline in function generally occurred within the first two years of disease onset. After progressing quickly, the rate of functional decline usually started to taper off [3].

Over the past two decades, a growing emphasis has been put on arthritis self-management strategies to help patients with RA to cope with the consequences of the disease [4] [5].

Therapeutic education is a set of activities designed to increase patients' knowledge about the disease [6], to help them to organize the treatment regimens and to acquire the abilities necessary for self-management of the consequences of the disease [7].

In Iraq, it was assumed that RA patients had some knowledge about their disease and its consequences, that the educational standard of the patients may influence the amount of knowledge and awareness of the disease, and that the frequency of hospital admissions may add to this knowledge. This study is probably the first one to verify these assumptions.

\section{Patients and Methods}

This was a cross-sectional study. All patients with an established diagnosis of RA who have access to the Department of Rheumatology in Baghdad Teaching Hospital, a tertiary referral center in Iraq were included. The diagnosis of RA depends on fulfilling the American College of Rheumatology (ACR) Criteria for the classification of RA [1].

Data collection took place between September 2011 and March 2012. A systematic random sample of 100 patients with RA was recruited.

\subsection{Ethical Considerations}

The study was granted full ethical approval from the Directorate General of Medical City Committee for Medical Ethics and Research. A signed informed consent was secured from all study participants. Privacy was assured during personal interview and identifying information was concealed during statistical analyses.

\subsection{Data Collection}

Patient's data were obtained by personal interview performed by the fourth author. RA disease-related data, such as disease duration, drug use (all anti-rheumatic drugs, glucocorticoids use and non steroidal anti-inflammatory drugs (NSAIDs)), physiotherapy, were collected.

Disease activity was measured using the Disease Activity Score based on evaluation of 28 joints (DAS28) [8]. A score of DAS28 $\leq 5.1$ is considered as the cut-off for low disease activity (including mild and moderate activity), whereas DAS28 $>5.1$ is considered as high disease activity.

Functional status was assessed according to the criteria for classification of functional status in rheumatoid arthritis [8]. The demographic characteristics included age, gender, marital status, occupation, academic level, number of years with RA, and socioeconomic status.

The scale used in the current study for measuring correct knowledge and favorable attitude was locally developed by the research team to match the level of comprehension for the majority of patients visiting the outpatient Rheumatology clinic in a governmental (free of charge) hospital.

Validity was assessed by the consensus of a panel of 5 senior Rheumatologists with long experience in dealing with local patients. A statistical assessment of reliability was not suitable, since the total score represents a summation of widely variable domains of knowledge and attitude.

\subsection{Statistical Analysis}

Statistical Package for Social Sciences (SPSS version 20) software was used. Frequency distribution for selected 
variables was done first. The statistical significance of difference in mean between 2 groups was assessed by independent samples t-test, while between more than 2 groups ANOVA test was used. Quantitative variables were converted into ordered categorical variables using the unbiased method of "Quintiles". P value less than the 0.05 level of significance was considered statistically significant. The statistical significance, direction and strength of linear correlation between 2 quantitative variables, one of which being non-normally distributed was measured by Spearman's rank linear correlation coefficient

\section{Results}

There were 100 patients with rheumatoid arthritis. Majority of patients were females (83\%) aged (40 - 59) years. More than two thirds (69\%) of patients were married, housewives constituted $64 \%$ of the total sample. Illiterates constituted a noticeable proportion (31\%), while only $16 \%$ had university level of education, Table 1.

The disease severity indices were also summarized in Table 2; $40 \%$ of the patients were of functional class II,

\section{Table 1. Frequency distribution of the study sample by socio-demographic variables.}

\begin{tabular}{|c|c|c|}
\hline & $\mathbf{N}$ & $\%$ \\
\hline \multicolumn{3}{|l|}{ Age group (years) } \\
\hline$<40$ & 23 & 23.0 \\
\hline $40-59$ & 59 & 59.0 \\
\hline $60+$ & 18 & 18.0 \\
\hline Total & 100 & 100.0 \\
\hline \multicolumn{3}{|l|}{ Gender } \\
\hline Female & 83 & 83.0 \\
\hline Male & 17 & 17.0 \\
\hline Total & 100 & 100.0 \\
\hline \multicolumn{3}{|l|}{ Marital status } \\
\hline Single & 14 & 14.0 \\
\hline Married & 69 & 69.0 \\
\hline Divorced & 1 & 1.0 \\
\hline Widowed & 16 & 16.0 \\
\hline Total & 100 & 100.0 \\
\hline \multicolumn{3}{|l|}{ Occupation } \\
\hline Skilled & 10 & 10.0 \\
\hline Unskilled labor & 4 & 4.0 \\
\hline Shop owner & 2 & 2.0 \\
\hline Clerk & 4 & 4.0 \\
\hline Professional & 2 & 2.0 \\
\hline Unemployed/housewife & 77 & 77.0 \\
\hline Student & 1 & 1.0 \\
\hline Total & 100 & 100.0 \\
\hline \multicolumn{3}{|l|}{ Educational level } \\
\hline Illiterate & 31 & 31.0 \\
\hline Read and write & 10 & 10.0 \\
\hline Primary school & 25 & 25.0 \\
\hline Secondary school & 18 & 18.0 \\
\hline College & 16 & 16.0 \\
\hline Total & 100 & 100.0 \\
\hline
\end{tabular}


Table 2. Frequency distribution of the study sample by disease severity indices.

\begin{tabular}{|c|c|c|}
\hline & $\mathbf{N}$ & $\%$ \\
\hline \multicolumn{3}{|l|}{ Functional class } \\
\hline Class I & 16 & 16.0 \\
\hline Class II & 40 & 40.0 \\
\hline Class III & 34 & 34.0 \\
\hline Class IV & 10 & 10.0 \\
\hline Total & 100 & 100.0 \\
\hline \multicolumn{3}{|l|}{ Disease activity (DAS28 score categories) } \\
\hline Low disease activity $(\leq 3.2)$ & 15 & 15.0 \\
\hline Moderate disease activity (3.2 - 5.1) & 39 & 39.0 \\
\hline High disease activity $(>5.1)$ & 46 & 46.0 \\
\hline Total & 100 & 100.0 \\
\hline \multicolumn{3}{|c|}{ Duration of the disease in year-categories (quartiles) } \\
\hline First quartile (lowest) $\leq 2$ & 25 & 25.0 \\
\hline Interquartile range (average) 2.1 - 12 & 50 & 50.0 \\
\hline Fourth quartile (highest) $>12$ & 25 & 25.0 \\
\hline Total & 100 & 100.0 \\
\hline \multicolumn{3}{|c|}{ Count of hospital admissions during the last year-categories } \\
\hline None & 65 & 65.0 \\
\hline Once & 15 & 15.0 \\
\hline $2+$ & 20 & 20.0 \\
\hline Total & 100 & 100.0 \\
\hline
\end{tabular}

$34 \%$ had class III and 16\% in class I and 10\% in class IV. Disease Activity indices were also summarized in the same table, as well as the frequency of hospital admissions.

The patient's knowledge and attitude to selected items were summarized by Table 3 . Twenty percent didn't know why the investigations were needed, $40 \%$ of patients didn't know the side effect of the medications, while $49 \%$ of cases didn't have knowledge about treatment types, Table 3. It had been found that only $6 \%$ correctly identify the nature of RA as autoimmune disease, Table 4.

The total score of the knowledge and attitude was calculated by summing the scores shown in Table 4 and Table 5.

The calculation of total knowledge and attitude score depends on summing the scores on items presented in the heading of Table 4 and Table 5 for each study subject. Each item in Table 4 is given a score of 1 for correct knowledge item and favorable attitude item, while a score of 1 to 2 is given to each item in Table 5 depending on the amount (extent) of correct knowledge in each knowledge domain. For the sake of making the score easily substantiated, the total score is weighted again to have a maximum of 10 instead of 13 by multiplying the score resulting from summation process by (10/13).

It was revealed that about $76 \%$ of the patients had a total score of less than 5 (the maximum score is 10 ), and the remaining $24 \%$ had a total score of 5 - 8 , Table 6.

Age, gender, Academic level, disease duration, activity and severity in addition frequency of hospital admissions had no important association with knowledge or attitude towards RA, Table 7.

\section{Discussion}

Females were consisting of the majority of the patients (83\%). These findings are in line with other studies and 
Table 3. Frequency distribution of the patient's responses to selected knowledge and attitude items (patient's perspectives and awareness).

\begin{tabular}{|c|c|c|}
\hline & $\mathbf{N}$ & $\%$ \\
\hline \multicolumn{3}{|l|}{ Auto-medication $(\mathrm{n}=100)$} \\
\hline Use treatment over the counter (without medical advice) & 17 & 17.0 \\
\hline Leave treatment against medical advice & 27 & 27.0 \\
\hline Consult paramedics & 9 & 9.0 \\
\hline Accept the opinion of lay people & 5 & 5.0 \\
\hline \multicolumn{3}{|l|}{ Knowledge about the reason for investigations $(n=100)$} \\
\hline Investigations that monitor disease activity and drug efficacy & 72 & 72.0 \\
\hline Investigations that monitor drug safety & 29 & 29.0 \\
\hline Don’t know & 20 & 20.0 \\
\hline \multicolumn{3}{|l|}{ Side effects of medications used for RA $(n=100)$} \\
\hline Anemia & 9 & 9.0 \\
\hline Kidney problems & 21 & 21.0 \\
\hline Impaired immunity & 4 & 4.0 \\
\hline Liver problems & 16 & 16.0 \\
\hline GIT problems & 29 & 29.0 \\
\hline Don’t know & 40 & 40.0 \\
\hline Other problems & 16 & 16.0 \\
\hline \multicolumn{3}{|l|}{ Knowledge about other tissues affected by RA $(n=100)$} \\
\hline Nervous system & 5 & 5.0 \\
\hline Gastrointestinal system & 11 & 11.0 \\
\hline Respiratory system & 8 & 8.0 \\
\hline Skin & 1 & 1.0 \\
\hline Cardio-vascular system & 11 & 11.0 \\
\hline Bones & 1 & 1.0 \\
\hline Others & 15 & 15.0 \\
\hline \multicolumn{3}{|l|}{ Reported treatment types known to patients $(n=100)$} \\
\hline NSAID & 29 & 29.0 \\
\hline Cytotoxic drugs & 32 & 32.0 \\
\hline Biological agents & 7 & 7.0 \\
\hline Alternative medicine (herbals, acupunctures, clergyman, praying) & 5 & 5.0 \\
\hline Don’t know & 49 & 49.0 \\
\hline
\end{tabular}

literatures; Jorit et al. [9] and Verstappen et al. [10] who found that the majority of cases were females (86\%) with a median age of (53) year.

Housewives formed (64\%) of the study sample, quite different from western countries, this obviously is due to the differences in cultural and environmental factors between our society and the western societies [4] [5]. 
Table 4. Relative frequency of patient's correct knowledge and favorable attitude towards the disease.

\begin{tabular}{ccc}
\hline Total $\mathbf{n}=\mathbf{1 0 0}$ & $\mathbf{N}$ & $\mathbf{\%}$ \\
\hline Correctly identify the nature of RA as autoimmune disease & 6 & 6.0 \\
Correctly identify changes in weather as an aggravating factor & 86 & 86.0 \\
Correctly identify smoking habit as an aggravating factor & 22 & 22.0 \\
Favorable attitude towards auto-medication (not start auto-medication/not stopping a medically & 61 & 61.0 \\
prescribed medication) & 87 & 87.0 \\
Favorable attitude (not accepting paramedics opinion, or other lay people opinion)
\end{tabular}

Table 5. Frequency distribution of the study sample by score evaluation of selected knowledge items.

\begin{tabular}{|c|c|c|}
\hline & $\mathbf{N}$ & $\%$ \\
\hline \multicolumn{3}{|l|}{ Correct knowledge about indications for lab investigations } \\
\hline Incorrect & 20 & 20.0 \\
\hline Score $=1$ (One correct indication) & 59 & 59.0 \\
\hline Score $=2$ (Two correct indications) & 21 & 21.0 \\
\hline \multicolumn{3}{|l|}{ Correct knowledge about side effects of medication } \\
\hline Incorrect & 51 & 51.0 \\
\hline Score $=1$ ( $1-2$ side effects reported $)$ & 43 & 43.0 \\
\hline Score $=2(3+$ side effects correctly reported $)$ & 6 & 6.0 \\
\hline \multicolumn{3}{|c|}{ Correct knowledge about other tissues and organs affected by RA apart from joints } \\
\hline Incorrect & 70 & 70.0 \\
\hline Score $=1$ (Knows about other organs affected by RA) & 27 & 27.0 \\
\hline Score $=2$ (Can list at least two site affected) & 3 & 3.0 \\
\hline \multicolumn{3}{|l|}{ Correct knowledge about drug options for RA } \\
\hline Incorrect & 54 & 54.0 \\
\hline Score $=1$ (Identifies only one type of drugs) & 29 & 29.0 \\
\hline Score $=2$ (Identifies 2 - 3 drug options) & 17 & 17.0 \\
\hline Total & 100 & 100.0 \\
\hline
\end{tabular}

Table 6. Cumulative frequency distribution of total knowledge and attitude score.

\begin{tabular}{cccc}
\hline Total knowledge and attitude score $(\mathbf{m a x}=\mathbf{1 0})$ & $\mathbf{N}$ & $\mathbf{\%}$ & Cumulative \% \\
\hline 1.5 & 7 & 7.0 & 7.0 \\
2.3 & 13 & 13.0 & 20.0 \\
3.1 & 23 & 23.0 & 43.0 \\
3.8 & 17 & 17.0 & 60.0 \\
4.6 & 16 & 16.0 & 76.0 \\
5.4 & 11 & 11.0 & 87.0 \\
6.2 & 7 & 7.0 & 94.0 \\
6.9 & 5 & 5.0 & 99.0 \\
7.7 & 1 & 1.0 & 100.0 \\
\hline
\end{tabular}


Table 7. The mean total knowledge and attitude score by selected independent variables.

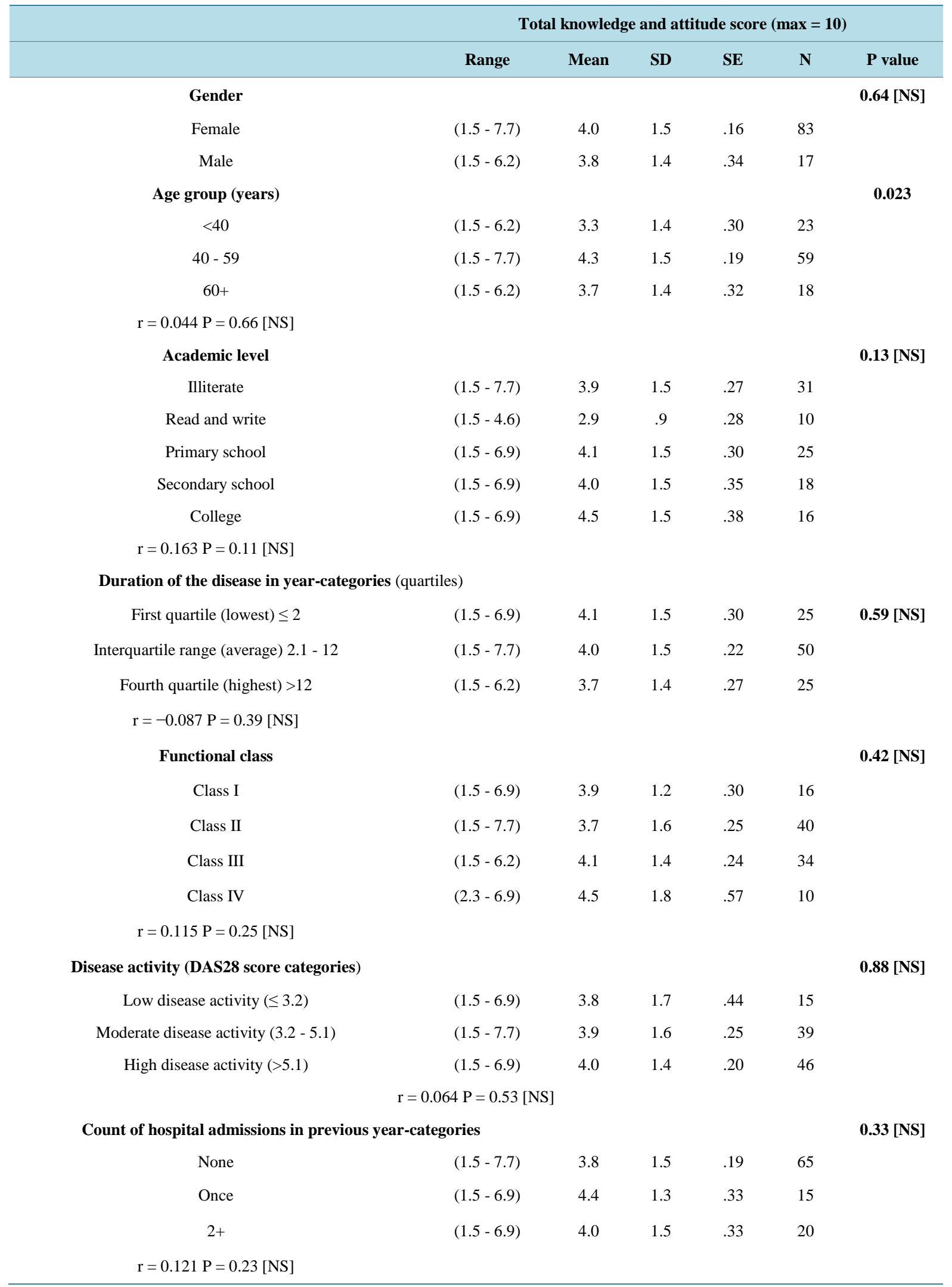


The educational level of the patients was distributed into 5 categories: (31\%) illiterates, (10\%) read and write, (25\%) primary school, (18\%) secondary school and (16\%) of cases had university level of education (Table 1); this coincides with findings of other studies [5]-[7].

Historically, a study from Iraq (Al-Jumaili et al. 1998) [11] was the first to address the educational level of patients with Rheumatoid Arthritis. His study didn't address the disease activity of the patients, but emphasized on the social and economic burden on the families of the sufferers, which is different from the scope of our study.

The total scores of the knowledge and attitude of the patients had revealed that about $76 \%$ of the cases had a total score less than 5 (the maximum is 10) and the remaining 24\% of the cases had a total score of 5 - 8 . In general About $80 \%$ of the patients had the knowledge about at least one indication for lab investigation, $49 \%$ of the patients did correctly identify one or more side effects of medication while $51 \%$ did not identify any side effect of the medications they were regularly taking. Interestingly, $54 \%$ of the patients couldn't identify even one type of drugs that they were regularly taking.

These findings were closer to that of Hill et al. (UK) [12], who found that $62 \%$ of patients knew that the cause of RA is, as yet, unknown but $27 \%$ thought it could be caused by injury and $11 \%$ by cold damp weather. Fifty two percent of the patients had no idea why they had blood tests. Almost all patients were taking some form of medication but there was widespread confusion about disease-modifying drugs and non-steroidal anti-inflammatory drugs (NSAIDs) [12].

Two interesting outcomes from this study were as follows: the first one is that illiterate patients had a mean knowledge and attitude scores of (3.9), which was not different from those who had a college certificate! This shows the need for patient's education about RA. The other interesting finding was that successive hospital admissions didn't make any difference to the total knowledge and attitude scores, i.e. those who had at least two admissions in hospital had an almost similar knowledge to those who were never admitted into the hospital. This reflects the lack of enthusiasm towards patient's education and counseling on the part of the medical and nursing staff.

\section{Conclusions}

- Patients' knowledge about RA was clearly deficient (more than 3 quarters had less than $50 \%$ of correct knowledge and favorable attitude).

- Age, gender, educational level, disease duration, activity and severity in addition to count of hospital admissions had no important relations with knowledge or attitude towards RA.

\section{Recommendations}

Formal patients education sessions may enhance the patients' awareness of the treatment and hence compliance, and might achieve better results in reducing the disease severity.

\section{References}

[1] Waldenburger, J.M. and Firestein, G.S. (2008) Rheumatoid Arthritis. In: Klippel, J.H., Stone, J.H., Crofford, L.J. and White, P.H., Eds., Primer on Rheumatic Diseases, 13th, Springer Science and Business Media, New York, 122-32.

[2] Al-Rawi, Z.S., Alazzawi, A.J., Al-Ajilli, F.M., et al. (1978) Rheumatoid Arthritis in Population Samples in Iraq. Annals of the Rheumatic Diseasess, 37, 73-75. http://dx.doi.org/10.1136/ard.37.1.73

[3] Hallert, E., Thyberg, I. and Hass, U. (2003) Comparison between Women and Men with Recent Onset Rheumatoid Arthritis of Disease Activity and Functional Ability over Two Years (the TIRA Project). Annals of the Rheumatic Diseases, 62, 667-670. http://dx.doi.org/10.1136/ard.62.7.667

[4] Isenberg, D.A. (2004) Oxford Textbook of Rheumatology. Oxford University Press, Oxford.

[5] Taal, E., Rasker, J.J. and Wiegman, O. (1996) Patient Education and Self-Management in the Rheumatic Diseases: A Self-Efficacy Approach. Arthritis \& Rheumatism, 9, 229-238. http://dx.doi.org/10.1002/1529-0131(199606)9:3<229::AID-ANR1790090312>3.0.CO;2-U

[6] Golay, A., Lagger, G., Chambouleyron, M., et al. (2005) Therapeutic Education of the Diabetic Patient. Diabetes/Metabolism Research and Reviews, 60, 599-603.

[7] Tall, E., Rasker, J.J. and Wiegman, O. (2007) Group Education for Rheumatoid Arthritis Patients. Seminars in Arthritis 
and Rheumatism, 26, 805-816. http://dx.doi.org/10.1016/S0049-0172(97)80024-8

[8] van der Heijde, D.M., van’t Hof, M.A., van Riel, P.L., et al. (1990) Judging Disease Activity in Clinical Practice in Rheumatoid Arthritis: First Step in the Development of a Disease Activity Score. Annals of the Rheumatic Diseasess, 49, 916-920. http://dx.doi.org/10.1136/ard.49.11.916

[9] Meesters, J.J.L., Theodora, P.M., Ylieland, V., Hill, J. and Ndosi, M.E. (2009) Measuring Educational Needs among Patients with Rheumatoid Arthritis Using the Dutch Version of the Educational Needs Assessment Tool (DENAT). Clinical Rheumatology, 28, 1073-1077http://dx.doi.org/10.1007/s10067-009-1190-3

[10] Verstappen, S.M.M., et al. (2007) Trends in Economic Consequences of Rheumatoid Arthritis over Two Subsequent Years. Rheumatology, 46, 968-974. http://dx.doi.org/10.1093/rheumatology/kem018

[11] Al-Jumaily, H.F., Salman, S. and Al-Tawil, W. (1998) Physical and Social Activities Influencing Family Relationships among Married Female Patients with Rheumatoid Arthritis. A Dissertation Submitted to the Scientific Council of Community Medicine.

[12] Hill, J., Bird, H.A., Hopkins, R., Lawton, C. and Wright, V. (1991) The Development and Use of a Patient Knowledge Questionnaire in Rheumatoid Arthritis. Rheumatology, 30, 45-49. http://dx.doi.org/10.1093/rheumatology/30.1.45 
Scientific Research Publishing (SCIRP) is one of the largest Open Access journal publishers. It is currently publishing more than 200 open access, online, peer-reviewed journals covering a wide range of academic disciplines. SCIRP serves the worldwide academic communities and contributes to the progress and application of science with its publication.

Other selected journals from SCIRP are listed as below. Submit your manuscript to us via either submit@scirp.org or Online Submission Portal.
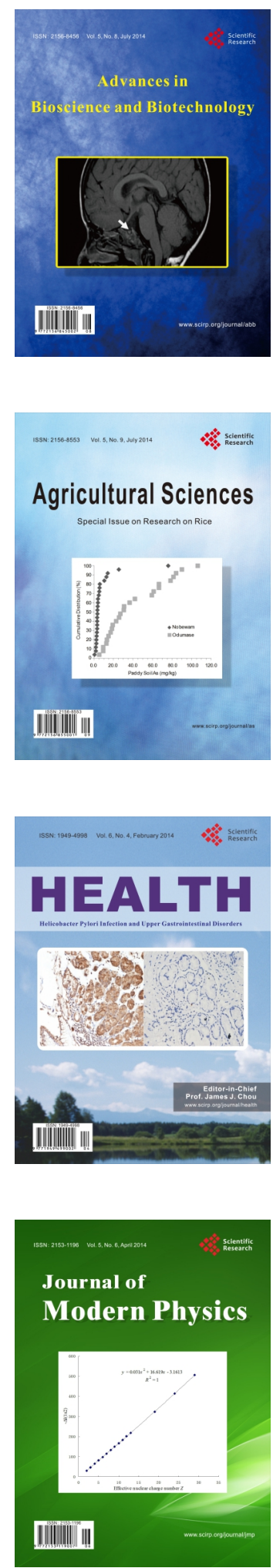
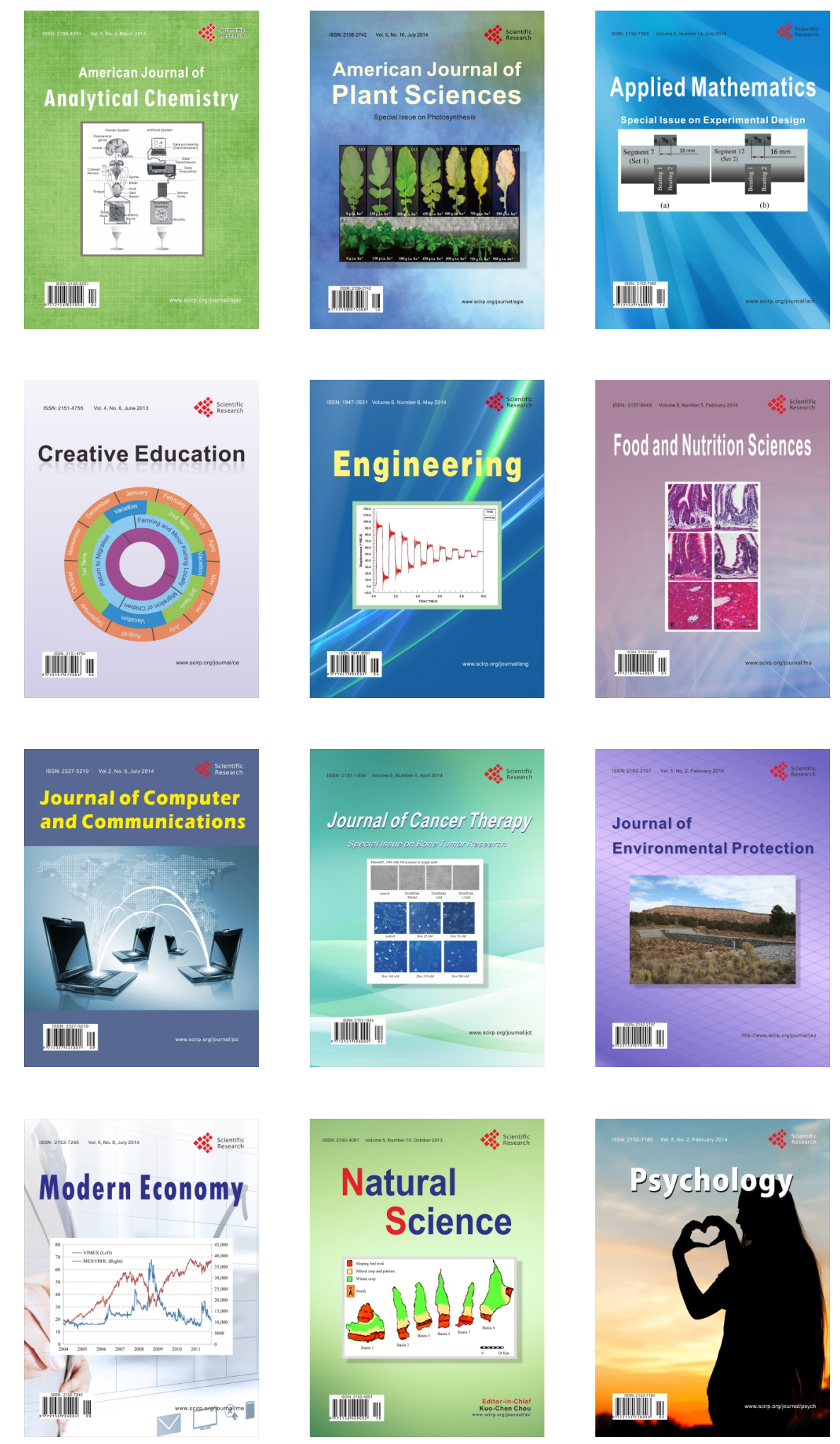